\title{
Correction: Feasibility of quantitative analysis of colonic perfusion using indocyanine green to prevent anastomotic leak in colorectal surgery
}

\author{
Juan-Carlos Gomez-Rosado ${ }^{1}$ (1) - Javier Valdes-Hernandez ${ }^{1}$. Juan Cintas-Catena ${ }^{1}$ - Auxiliadora Cano-Matias ${ }^{1}$. \\ Asuncion Perez-Sanchez ${ }^{1}$. Francisco-Javier del Rio-Lafuente ${ }^{1} \cdot$ Cristina Torres-Arcos $^{1} \cdot$ Yaiza Lara-Fernandez $^{2}$. \\ Luis-Cristobal Capitan-Morales ${ }^{1} \cdot$ Fernando Oliva-Mompean $^{1}$
}

Published online: 9 February 2022

(c) The Author(s), under exclusive licence to Springer Science+Business Media, LLC, part of Springer Nature 2022

\section{Correction to: Surgical Endoscopy (2021) 36:1688-1695 https://doi.org/10.1007/s00464-021-08918-9}

This article was updated to correct the sentence in the Discussion section which now reads "As observed in our experience, in 16(23.2\%) patients..." (rather than "As observed in our experience, in $8(11.5 \%)$ patients...").

Publisher's Note Springer Nature remains neutral with regard to jurisdictional claims in published maps and institutional affiliations.

The original article can be found online at https://doi.org/10.1007/ s00464-021-08918-9.

Juan-Carlos Gomez-Rosado

dr.gomez.rosado@gmail.com

1 Colorectal Surgery Unit, General and Digestive Surgery, University Hospital Virgen Macarena, Dr Fedriani s/n, 41009 Seville, Spain

2 General and Digestive Surgery, University Hospital Virgen Macarena, Seville, Spain 